\title{
Editorial 33
}

\author{
Eric R. Scerri
}

Published online: 29 September 2009

(c) Springer Science+Business Media B.V. 2009

The development of the philosophy of chemistry is of course dependent upon the continued research among philosophers, historians and educators with an interest in the fundamental aspects of chemistry. But this is not all that there is to the field. Since founding this journal about 12 years ago it has always been my aim to interest mainstream chemists in the value of philosophical reflection upon chemical ideas and practices. The very title of the journal, Foundations of Chemistry, was chosen partly to parallel that of the earlier established Foundations of Physics, which publishes articles mainly by professional physicists with an interest in foundational issues.

It is with great pleasure therefore that we present in this issue another article from a professional chemist, Jozef Sima from the Slovak Republic. Sima is interested in the limits of the notion of oxidation state, a concept that lies at the heart of inorganic chemistry in particular. He examines the possibilities of exceeding the currently accepted range of oxidation states ( - IV to + VIII). He considers various methods which allow one to assign oxidation numbers, which as Sima readily concedes is a man-made concept. His motivation is both technical and educational since as Sima explains, chemistry textbooks are notorious for propagating chemical dogma. Such was the case with books written prior to 1962 in which the possibility of noble gas compounds was never even discussed.

In a similar vein, the second article in this issue speaks to the question of philosophy of chemistry with an emphasis on the technical details of another branch of the subject, namely quantum chemistry. As I and others have argued since the modern resurgence of philosophy of chemistry, it is important to relate closely to the chemical practice of theorists rather than to retreat to cozy conversations among philosophers concerning highly abstract issues in analytical philosophy. We must not allow our field of interest to become so autonomous as to be even more ignored by chemists that it is at present. ${ }^{1}$

\footnotetext{
${ }^{1}$ I am exaggerating a little, and in fact there are recent signs of philosophy of chemistry reaching an everwider audience of chemists. See for example the recent article by Wand and Schwarz (2009) in Angewandte Chemie and an article in Chemical \& Engineering News for October, 15th, 2009.
}

E. R. Scerri $(\bowtie)$

Department of Chemistry \& Biochemistry, UCLA, 607 Charles Young Drive East, Los Angeles, CA 90095, USA

e-mail: scerri@chem.ucla.edu 
But not all contemporary philosophers of chemistry share my view about the need to examine the quantum mechanical aspects of chemistry and questions of the reduction of chemistry. Most notably, Bernadette Bensaude-Vincent has consistently attacked the view that the question of the reduction of chemistry to physics is of central importance to our new field. In a number of publications she has tried to argue that a genuine philosophy of chemistry should be founded on what makes chemistry unique, namely features like the synthesis of new materials, the essentially practical nature of chemistry and the apparent emergence of properties as a result of compound formation (Bensaude-Vincent 2008).

While Bensaude-Vincent's view clearly has some merit, she fails to realize that most working chemists will not entertain any views of emergence while the current reductive paradigm continues to be so successful in providing an essential working tool for chemists, including the creation of new compounds. It is not by promoting internal dialogues on the nature of mixis, one of the topics that she believes is so important, but by meeting modern chemistry on its own terms that philosophy of chemistry will make its mark.

But let me finally get off my soap-box to return to the paper I am introducing. Hinne Hettema, a previous contributor writing from New Zeeland on the subject of chemical bonding, takes up a suggestion of mine. He undertakes an assessment of the reduction of chemistry in a naturalistic manner that I attributed to Popper, meaning by examining what quantum chemists actually do. Hettema carries this program forward by not only considering error bounds, as I had begun to do, but by widening the approach to consider some key enabling theorems such as the Ehrenfest and Virial theorems. Moreover Hettema's approach involves a partial return to the Nagelian view of reduction, which will no doubt please some readers here.

This issue also sees the welcome return of book reviews to the journal. This is entirely due to our having finally found a suitable replacement for the previous review editor, John Bloor. The new review editor is the energetic Peter Thyssen from the Catholic University of Leuven.

The first review is written by Robert DeKosky, an expert on 19th century spectroscopy whose work I first became fully acquainted with following his review of my own book (DeKosky 2008). In the current review DeKosky given a masterly overview of the long-awaited biography of William Crookes, written by leading historian of chemistry William Brock.

Secondly, Lee McIntyre contributes a very generous review of my own recent collection of articles on the Philosophy of Chemistry.

The third review comes from Argentina, courtesy of Olimpia Lombardi and Martin Labarca two authors whose articles have appeared in the journal and which have provoked some lively discussion (Lombardi and Labarca 2005, 2006; Needham 2006). The book that they review in this issue consists of a collection of papers given at a conference in Leuven on the topic of 'stuff'. This approach represents something of a radical alternative to the talk of reduction to quantum mechanics and is more in keeping with the idea of examining questions that are peculiar just to chemistry. The editors of the excellent volume are Klaus Ruthenberg and Jaap van Brakel two old friends of this journal.

\section{References}

Bensaude-Vincent, B.: Essais d'histoire de philosophie de la chimie. Presses Universitaires de Paris Ouest, Paris (2008)

DeKosky, R.: Book review of Eric Scerri, the periodic table, its story and its significance, OUP, 2007. Ann. Sci. 65, 461-464 (2008) 
Lombardi, O., Labarca, M.: The ontological autonomy of the chemical world. Found. Chem. 7, 125-148 (2005)

Lombardi, O., Labarca, M.: The ontological autonomy of the chemical world: a response to Needham. Found. Chem. 8, 81-92 (2006)

Needham, P.: Ontological reduction: a comment on Lombardi and Labarca. Found. Chem. 8, 73-80 (2006)

Wang, S.-G., Schwarz, W.H.E.: Icon of chemistry: the periodic system of the chemical elements in the new century. Angew. Chem. Int. Ed. 48, 3404-3415 (2009) 